\title{
Reinforcement of Plastic Waste with Treated Natural Fibers
}

\author{
Irene S. Fahim, Salah M. Elhaggar
}

Department of Mechanical Engineering, The American University in Cairo, Cairo, Egypt.

Email: \{rico4000, elhaggar\}@aucegypt.edu

Received November $3^{\text {rd }}$, 2011; revised December $5^{\text {th }}$, 2011; accepted December $17^{\text {th }}, 2011$

\begin{abstract}
Plastic wastes are a major environmental concern that needs to be dealt with to minimize the amount of municipal solid waste and depletion of natural resources thus enhancing the sustainability concept for future generations. The objective of this study is to enhance the properties of plastic products using plastic wastes reinforced with treated natural fibers such as rice straw as well as carbonized rice straw, using a simple and efficient technology.
\end{abstract}

Keywords: Polymers-Matrix Composites (PMCs); Recycled Polymer; Natural Fibers; Fiber Reinforced Plastic

\section{Introduction}

The market potential regarding the usage of plastic waste into other utilizations is huge due to the high amounts of its disposition which constitute the largest share of the global municipal solid waste (MSW). Plastics account for an increasing fraction of municipal solid waste around the world. In India, plastic in MSW makes up to $9 \%-12 \%$ by weight of the total in addition to other wastes that may contain higher proportions of plastics. The majority of plastic waste generated is landfilled. However the continuous growth of worldwide plastic consumption due to its short life cycle compared to other products; roughly $40 \%$ have duration of life cycle smaller than 1 month, and the legalizations of many countries concerned with minimizing landfills content and incinerators led to a necessity of recovering plastic waste instead of disposing [1]. Incineration and land filling alternatives were rejected by several countries due to their potential danger to the environment either by polluting air or land; which result in not closing the cradle to cradle loop and depleting natural resources [2]. In the United States, plastic had a total amount of 19.2 million tons in 2001, accounting for about $8.4 \%$ of total municipal solid wastes. Thus, used plastics are becoming a potential worldwide source of raw materials. As a consequence the tendency towards recycling has increased resulting in attempts for plastic recovery. While in 2005, the United States recycled around $5.7 \%$ of the total plastics generated. On the other hand, some states in the US like Michigan have a high recycling rate that accommodates all the waste produced. In Brazil, potential in recycling have been raised where $15 \%$ of all plastics consumed are recycled and returned to industry [3].
Even though the technologies and advancements with respect to recycling plastics have soared, there remains the unanswered question of cost. A study entitled "The Cost of Reducing Municipal Solid Waste" showed that the cost becomes an obstacle due to energy cost, transportation cost, sorting, labor cost but if done on a large scale it pays back [4]. After recycling the waste, it could be reinforced with natural fibers such as rice straw to enhance the mechanical properties. Rice straw can work well with recycled polymer as reinforcing filler.

Natural fibers have the advantages of low density, low cost, and biodegradability. However, the main disadvantages of natural fibers in composites are the poor compatibility between fiber and matrix and the relative high moisture sorption. Therefore, chemical treatments using acids or alkalis are considered in modifying the fiber surface properties. This improves the thermal stability of fibers, compatibility and interfacial bond stress. The treatment also removes any impurities of the fiber. Fiber treatment through carbonization is a treatment for rice straw fibers in which heating without air occurs. The pore structure and adsorption properties of carbonized fibers are strongly used in several applications due to improved mechanical properties. The steps of carbonization include thermal treatment of raw fibers in an inert atmosphere followed by an activation step with $\mathrm{CO}_{2}$ or steam at the same temperature used. In chemical activation, the raw fibers were impregnated in a solution of phosphoric acid and heated at $900^{\circ} \mathrm{C}$ in an inert atmosphere. This chemical treatment leads to a high porosity, which enables a high adsorption capacity for micro pollutants. Moreover, it produces numeric acidic surface groups involved in the adsorption mechanism of dyes and metal ions. The phosphoric acid promotes the bond 
cleavage in the biopolymers and dehydration at low temperatures, followed by extensive cross linking that binds volatile matter into the carbon product and thus increase the carbon yield [5].

The choice to use an acid or alkali as a fiber treatment will depend on both the tensile and flexural tests together with the utilization of this waste after treatment. The uses of the acid and alkali solution were investigated in order to decide which acid or alkali should be used to treat rice straw. Phosphoric acid and sulphuric acid as an acid solution will be investigated as well as sodium hydroxide as an alkali to select the best treatment solution. The waste from phosphoric acid treatment is used to remove rust from surfaces of metals. It can be used as a rust converter with the help of direct application to rusted iron, or steel tools and other rusted surfaces. The phosphoric acid converts reddish-brown iron, that is, ferric oxide to black colored ferric phosphate. After treatment with phosphoric acid, the black ferric phosphate coating can be scrubbed off, thus, revealing fresh metal surface. Phosphoric acid is also used as an additive to acidify foods and beverages. Phosphoric acid is used as an ingredient in over-the-counter anti-nausea medications which also happen to contain high levels of sugar. In dentistry, this acid is combined with zinc powder to form zinc phosphate, which is used as dental cement. It is also used in orthodontics as an etching solution so as to clean and roughen the surface of teeth, before the placement of brackets and other dental appliances. This acid is also used in many teeth whitening solutions to eliminate plaque that may be present on the surface of teeth. Moreover, the manufacture of most commercial phosphate fertilizers begins with the production of phosphoric acid [6].

\section{Objective}

Plastic wastes are a major environmental concern that needs to be dealt with to minimize the amount of municipal solid waste, depletion of natural resources and enhancing the sustainability concept for future generations. The objective of this work is to enhance the properties of plastic waste through reinforcement with natural fiber such as rice straw, using a simple and effective technology. Rice straw will be treated using acids, alkali and carbonization treatment. The mechanical properties of plastic wastes reinforced with treated rice straw will be investigated using flexural, tensile stress tests. The synthesized recycled composites will be compared with the recycled polymer without reinforcement to observe the effect of reinforcement on the mechanical properties of the composite.

\section{Mechanical Testing}

There are several tests that can be selected for fiber rein- forced polymers. Flexural and tensile stress was chosen, as they are the ultimate range that the product can sustain under severe usage conditions. In addition, they are of a major importance for many international codes related to construction and mechanical application. Tensile stress is the maximum stress that a material can withstand while being stretched or pulled before necking, when the specimen's cross-section starts to significantly contract. It is found by performing a tensile test and recording the stress versus strain; the highest point of the stress-strain curve is the ultimate tensile stress. The Instron machine used in the experimental procedure is 3300 Instron as shown in Figure 1. Instron is a testing machine having properties of performing tensile, compression, flex, peel and cyclic type of testing. It is available at the AUC testing labs and was utilized to perform flexural and tensile tests. First the two edges of the machine consist of the support span, where the grips are attached to the load ram and the specimen was concentrated between the support edges. After adjusting the computer, software settings, the machine was ordered to start the test and the ram moved downwards applying the load. The output of the test is a stress-strain diagram. Tension samples were selected according to (ASTM D3039/D 3039M-00) [7]:

- Width $=20 \mathrm{~mm}$

- Length $=100 \mathrm{~mm}$

- Thickness = Approx. $4.5-6.5 \mathrm{~mm}$

- Grip = $20 \mathrm{~mm}$

- Crosshead Speed $=5 \mathrm{~mm} / \mathrm{min}$

The flexural test is performed with 3-point loading, the specimen is loaded with one nose in the middle of the specimen support span; the distance between the 2 support edges as shown in Figure 2. Therefore the maximum axial fiber stress is positioned directly under the loading nose. The flexural stress represents the highest stress experienced within the material at its moment of rupture. It is measured in terms of stress. The equation for a rectangular sample under a load in a three-point bending: $\sigma=3 F L / 2 b d 2$ where $F$ is the load (force) at the fracture point, $L$ is the length of the support span, $b$ is width, $d$ is thickness. Bending samples were selected according to (ASTM D790-03) [7]:

- Width $=20 \mathrm{~mm}$

- Thickness = Approx. $4.5-6.5 \mathrm{~mm}$

- Span $=16 \times$ Thickness

- Crosshead Speed $=2 \mathrm{~mm} / \mathrm{min}$

\section{Results}

\subsection{Flexural Stress}

The effect of chemical concentration with $2 \mathrm{~mm}$ fiber length on the reinforcement of recycled low density polyethylene (RLDPE) using phosphoric acid $\left(\mathrm{H}_{3} \mathrm{PO}_{4}\right)$ is shown in Figure 3. It is noticed that $1 \%$ concentration 


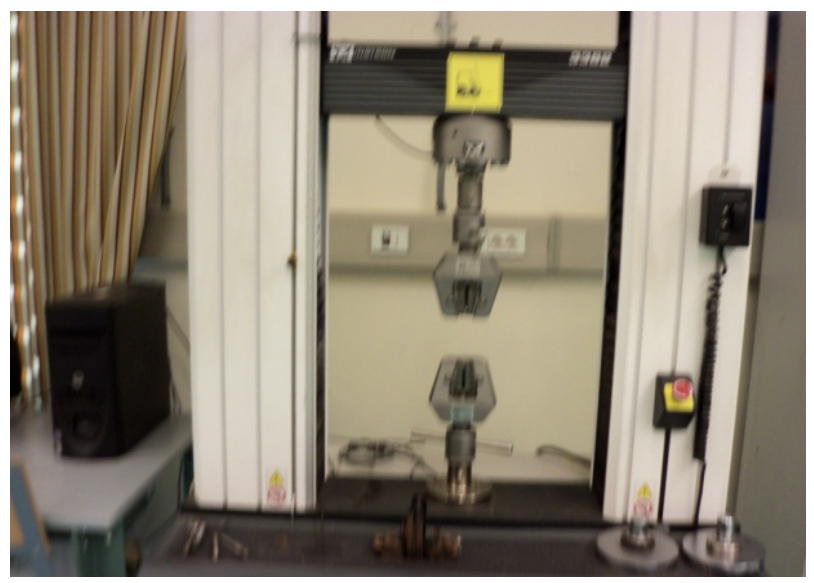

Figure 1. Instron Universal testing machine with tension grip.

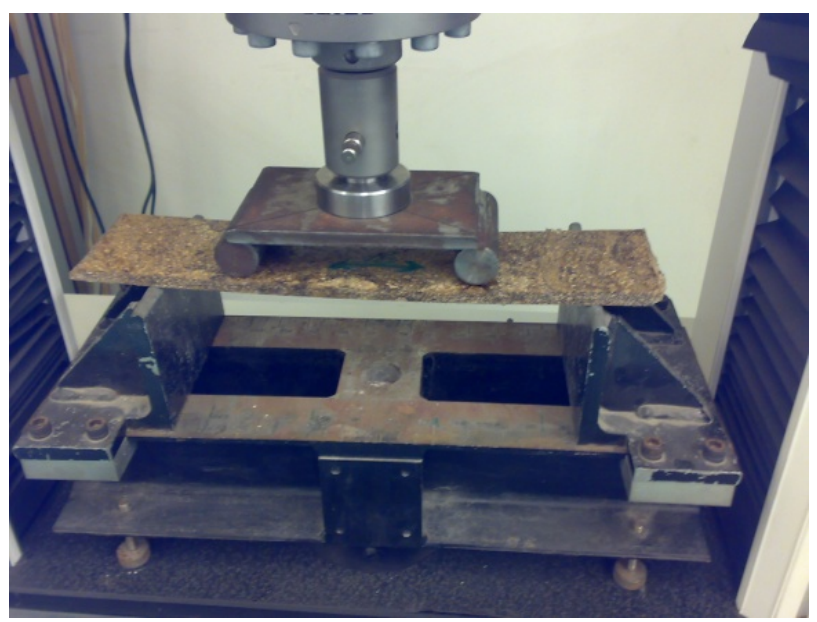

Figure 2. The flexural fixture with 3 point bending.

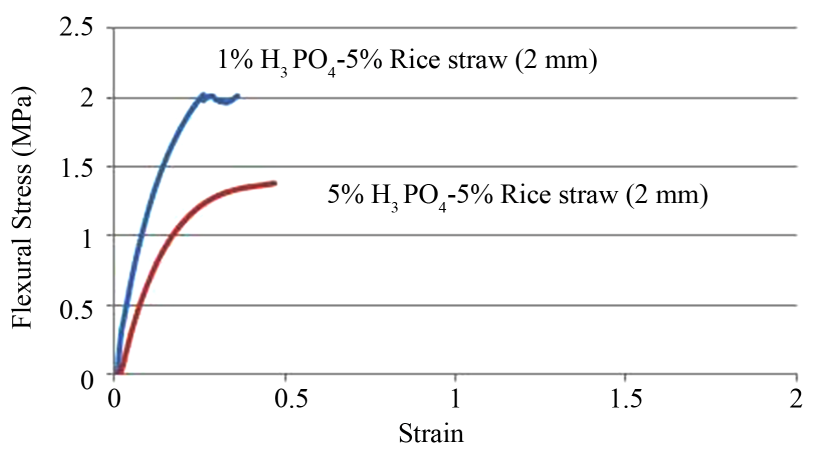

Figure 3. Effect of chemical conc. using $\mathrm{H}_{3} \mathrm{PO}_{4}$.

obtained higher flexural stress than using 5\% chemical concentration. $1 \%$ will be used in order to avoid the use of unneeded chemicals. The effect of fiber content 2, 5 and 6\% are tested with 2 mm length as shown in Figure 4. The recycled polymer without reinforcement yielded 1.2 MPa flexural stress. The most suitable sample is $5 \%$ rice straw of $2 \mathrm{~mm}$ length treated with $1 \%$ concentration of $\mathrm{H}_{3} \mathrm{PO}_{4}$ The increase in fiber content lowered the flexural stress as shown in Figure 4.

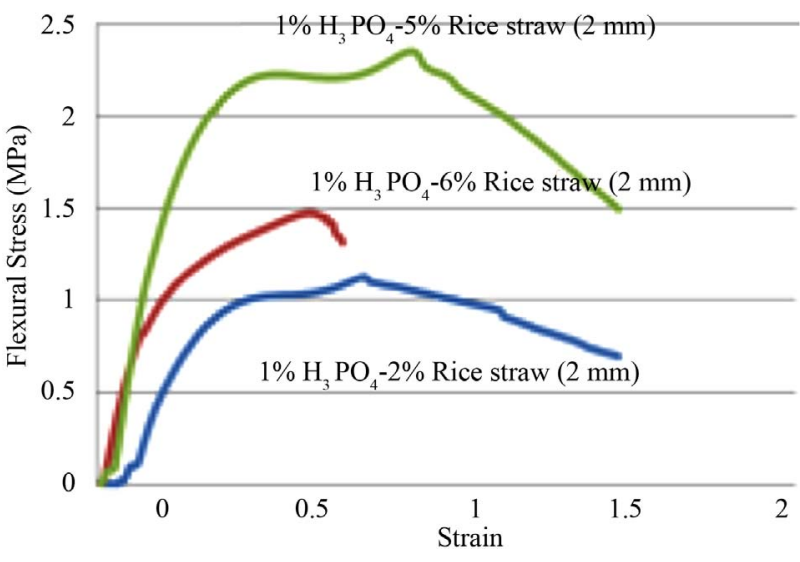

Figure 4. Effect of fiber content with $2 \mathrm{~mm}$ fiber length using $1 \% \mathrm{H}_{3} \mathrm{PO}_{4}$.

The effect of $5 \%$ of treated fiber content using 1\% chemical concentration with 2, 4 and $6 \mathrm{~mm}$ fiber length on the reinforcement of RLDPE is noticed in Figure 5. It showed that the effect of increasing fiber length leading to a decrease in flexural stress. At high fiber volume fractions, the material properties show greater variability due to fiber clumping. Also the fiber length decreases with increasing fiber content and this reduction in fiber length then reduces fiber reinforcing efficiency due to the increased fiber-fiber interaction and fiber-equipment wall contact. Moreover the increase in fiber content causes the formation of agglomerates acting as a stress focus and, therefore, as a propagator of cracks, resulting in the greater tenacity of the composites. Carbonization is another process used for treating natural fibers. The effect of treated carbonized fiber is investigated using 2 and $5 \%$ fiber content. The sample with the treated, carbonized 5\% rice straw with $2 \mathrm{~mm}$ size has higher flexural stress compared to the sample with 4 and $6 \mathrm{~mm}$ size according to Figure 6.

\subsection{Tensile Stress}

The effect of chemical concentration with $2 \mathrm{~mm}$ fiber length on the reinforcement of RLDPE using $\mathrm{H}_{3} \mathrm{PO}_{4}$ is noticed in Figure 7. The 1\% concentration obtained higher flexural stress than using 5\% chemical concentration. $1 \%$ will be used in order to avoid the use of unneeded chemicals. The effect of fiber content 2, 5 and $6 \%$ is tested with $2 \mathrm{~mm}$ length as shown in Figure 8. The recycled polymer without reinforcement yielded 1.5 $\mathrm{MPa}$ tensile stress. The increase in fiber content lowered the tensile stress. The effect of $5 \%$ of treated fiber content using $1 \%$ chemical concentration with 2, 4 and $6 \mathrm{~mm}$ fiber length on the reinforcement of RLDPE was investigated using tensile test. The use of $1 \%$ chemical concentration as it obtains almost the same stress as using 5\% chemical concentration. Figure 9 showed the effect of increasing fiber length leading to a decrease in flexural 


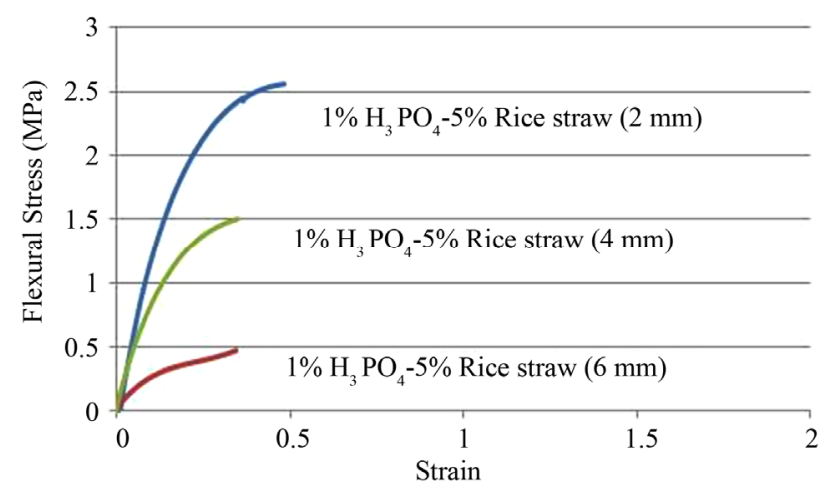

Figure 5. Effect of different fiber length using $5 \%$ fiber content and $1 \% \mathrm{H}_{3} \mathrm{PO}_{4}$.

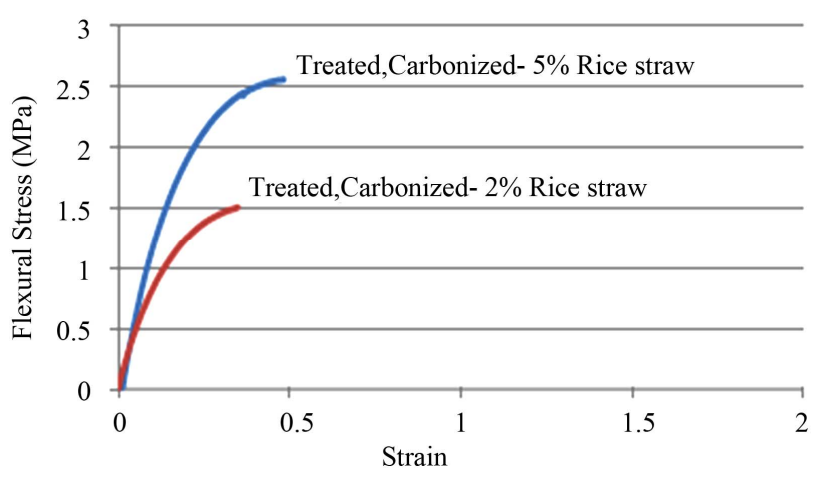

Figure 6. Effect of different treated, carbonized fiber content.

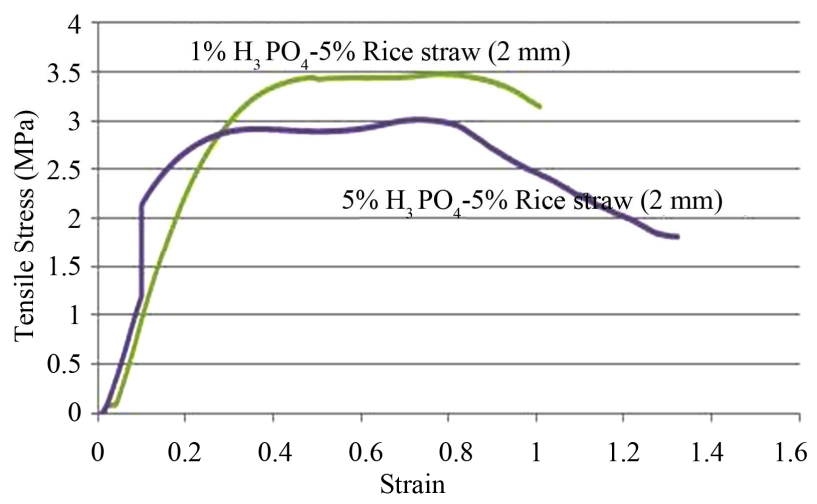

Figure 7. Effect of chemical conc. using $\mathrm{H}_{3} \mathrm{PO}_{4}$.

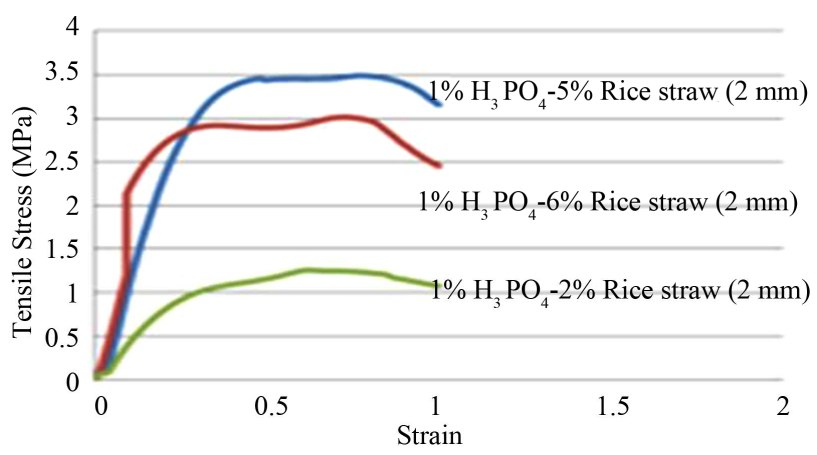

Figure 8. Effect of fiber content with $2 \mathbf{~ m m}$ fiber length and $1 \% \mathrm{H}_{3} \mathrm{PO}_{4}$.

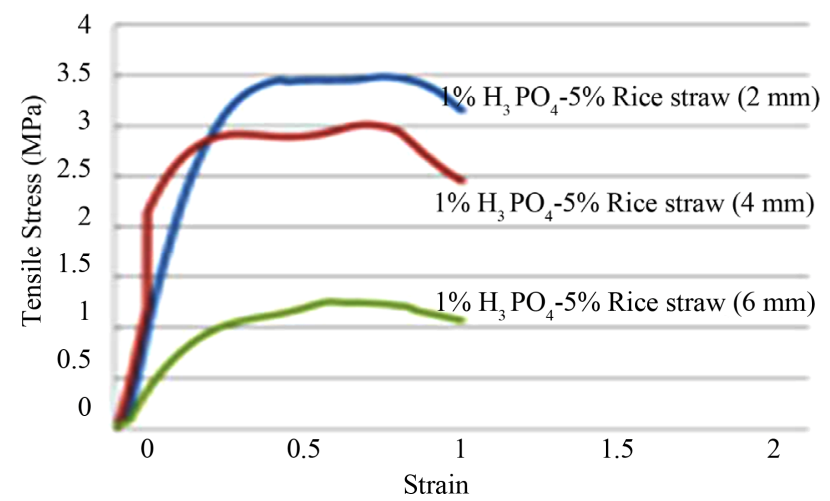

Figure 9. Effect of different fiber length using $5 \%$ fiber content and $1 \% \mathrm{H}_{3} \mathrm{PO}_{4}$.

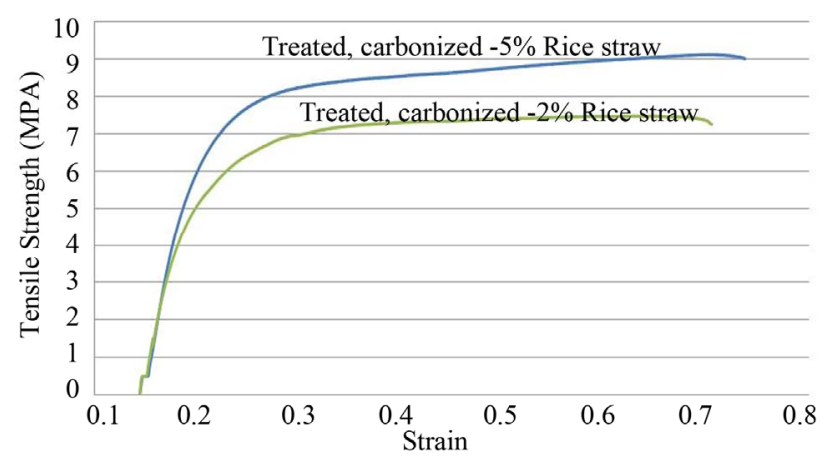

Figure 10. Effect of different treated, carbonized fiber content.

stress. The fibers are treated through carbonization. The effect of treated carbonized fiber is investigated using $2 \%$ and $5 \%$ fiber content. The sample with the treated, carbonized $-5 \%$ rice straw has higher tensile stress compared to 2\% fiber concentration according to Figure 10.

\section{Conclusion}

The mechanical properties of RLDPE increased three times due to the reinforcement with chemically treated rice straw. This composite can be used in several applications due to durability, environmental friendliness, ease of processing, high strength and flexibility. The effect of increasing the fiber concentration to $6 \%$ and decreasing it to $2 \%$ lowered both tensile and flexural thus $5 \%$ is the optimum fiber content. Moreover, the treatment of rice straw through carbonization was addressed as the tensile properties of the composite were enhanced by 9 times. The chemical treatment contributed to the formation of fibers with higher values of surface area and micro porosity. This carbonization enhanced the environmentally utilization of undesirable cellulosic wastes.

\section{REFERENCES}

[1] R. Kikuchi, J. Kukacka and R. Raschmn, "Grouping of Mixed Waste Plastics According to Chlorine Content," Separation and Purification Technology, Vol. 61, No. 1, 
2008, pp. 75-81. doi:10.1016/j.seppur.2007.10.001

[2] http://www.buzzle.com/articles/phosphoric-acid-uses.html

[3] K. B. Adhikary, S. Pang and M. P. Staiger, "Dimensional Stability and Mechanical Behavior of Plastic Composites Based on Recycled and Virgin LDPE," Composites: Part B, No. 39, 2008.

[4] K. Palmer, H. Sigman and M. Walls, "The Cost of reducing Municipal Solid Waste. Resources for the Future,”
Washington DC, 2007.

[5] http://cipet.gov.in/plastics_statics.html

[6] H. P. Ngoc, "Production of Fibrous Activated Carbons from Natural Cellulose for Water Treatment Applications,” Institute of Chemical Technology, Europe, 2006.

[7] ASTM, "Standard Guide for Testing Polymer Matrix Composite Materials,” ASTM Standards Source, Philadelphia, 2010. 